\title{
An Improved Particle Swarm Optimization with Biogeography- Based Learning Strategy for Economic Dispatch Problems
}

\author{
Xu Chen $\left(D,{ }^{1,2}\right.$ Bin Xu $\left(D,{ }^{3}\right.$ and Wenli Du ${ }^{2}$ \\ ${ }^{1}$ School of Electrical and Information Engineering, Jiangsu University, Zhenjiang, 212013 Jiangsu, China \\ ${ }^{2}$ Key Laboratory of Advanced Control and Optimization for Chemical Processes, Ministry of Education, East China University of \\ Science and Technology, Shanghai 200237, China \\ ${ }^{3}$ School of Mechanical Engineering, Shanghai University of Engineering Science, Shanghai 201620, China
}

Correspondence should be addressed to Xu Chen; xuchen@ujs.edu.cn

Received 3 April 2018; Revised 2 May 2018; Accepted 14 May 2018; Published 12 July 2018

Academic Editor: Zhile Yang

Copyright ( $\odot 2018 \mathrm{Xu}$ Chen et al. This is an open access article distributed under the Creative Commons Attribution License, which permits unrestricted use, distribution, and reproduction in any medium, provided the original work is properly cited.

\begin{abstract}
Economic dispatch (ED) plays an important role in power system operation, since it can decrease the operating cost, save energy resources, and reduce environmental load. This paper presents an improved particle swarm optimization called biogeographybased learning particle swarm optimization (BLPSO) for solving the ED problems involving different equality and inequality constraints, such as power balance, prohibited operating zones, and ramp-rate limits. In the proposed BLPSO, a biogeographybased learning strategy is employed in which particles learn from each other based on the quality of their personal best positions, and thus it can provide a more efficient balance between exploration and exploitation. The proposed BLPSO is applied to solve five ED problems and compared with other optimization techniques in the literature. Experimental results demonstrate that the BLPSO is a promising approach for solving the ED problems.
\end{abstract}

\section{Introduction}

Economic dispatch (ED) is an important optimization task in power system operation and planning. The main objective of ED problems is to allocate generation among the committed generating units so as to meet the required load demand at minimum operating cost, with various physical constraints [1]. The cost of power generation is high, and economic dispatch can help in saving a significant amount of revenue [2].

In the original ED problem, the cost function for each generation unit is approximately represented by a single quadratic function, and traditional approaches based on mathematical programming techniques have been utilized to solve the ED problem, including the lambda-iteration method, gradient method, Newton's method, linear programming, interior point method, and dynamic programming [3-5]. Usually, these methods are highly sensitive to starting points and rely on the assumption that the cost function needs to be continuous and convex. However, the practical ED problems exhibit nonconvex and nonsmooth characteristics because of valve-point effects, ramp-rate limit, multifuel cost, prohibited operating zones, and so on [6]. The traditional methods are not capable of efficiently solving the ED problems with these characteristics.

In the past decades, more and more researchers are turning to metaheuristic search (MS) algorithms for solving the ED problems. These methods have the ability to identify higher-quality solutions and can be grouped into three categories, as original, improved, and hybrid MS algorithms.

The first category consists of methods applied in their original version, such as genetic algorithm (GA) [7], particle swarm optimization (PSO) [8], differential evolution (DE) [9], ant colony optimization (ACO) [10], harmony search (HS) [11], artificial bee colony (ABC) [12], teachinglearning-based optimization (TLBO) [13], gravitational search algorithm (GSA) [14], firefly algorithm (FA) [15], biogeography-based optimization (BBO) [16, 17], bacterial foraging optimization (BFO) [18], imperialist competitive 
algorithm (ICA) [19], seeker optimization algorithm (SOA) [20], grey wolf optimization (GWO) [21], backtracking search algorithm (BSA) [22], and root tree optimization (RTO) [23].

The second refers to improved or modified methods derived from the original version, and the following are included: self-adaptive real-coded genetic algorithm (SARGA) [24], random drift PSO (RDPSO) [25, 26], fuzzy adaptive modified PSO (FAMPSO) [27], improved differential evolution (IDE) [28], shuffled differential evolution (SDE) [29], improved harmony search (IHS) [30], modified artificial bee colony (MABC) [31], incremental artificial bee colony (IABC) [32], ramp-rate biogeography-based optimization (RRBBO) [33], dynamic nondominated sorting biogeography-based optimization (Dy-NSBBO) [34], multistrategy ensemble biogeography-based optimization (MsEBBO) [35], and modified group search optimizer (MGSO) [36].

The third is the hybrid method in which two or more optimization techniques are combined, including hybrid genetic algorithm (HGA) [37], chaotic PSO with sequential quadratic programming (CPSO-SQP) [38], hybrid PSO and gravitational search algorithm (HPSO-GSA) [39], hybrid differential evolution algorithm based on PSO (DEPSO) [40], hybrid differential evolution with biogeography-based optimization (DE/BBO) [41], hybrid chemical reaction optimization with differential evolution (HCRO-DE) [42], and hybrid imperialist competitive-sequential quadratic programming (HIC-SQP) [43].

In this paper, an improved PSO algorithm with biogeography-based learning strategy is proposed to solve the ED problems. The main contributions of this paper are listed as follows:

(1) A biogeography-based learning particle swarm optimization (BLPSO) algorithm which employs a biogeography-based learning strategy (BLS) is presented. The computational complexity of BLPSO is also analyzed.

(2) By combining the feature of ED problems, the BLPSObased economic dispatch method is developed.

(3) BLPSO is applied to solve five ED problems with various practical constraints, and the experimental results demonstrate that the proposed method can obtain promising results for ED problems.

This paper is organized as follows: Section 2 briefly introduces the formulation of ED problems. Section 3 introduces the original PSO and its three variants. In addition, a biogeography-based learning particle swarm optimization algorithm is presented in this section. Section 4 addresses the implementation of BLPSO for solving ED problems. Section 5 provides the experimental results on five test systems. Finally, the paper is concluded in Section 6.

\section{Formulation of ED Problems}

The objective of the ED problem is to minimize the fuel cost of thermal power plants for a given load demand subject to various physical constraints.
2.1. Objective Function. The traditional fuel cost or objective function of the ED problem is the quadratic fuel cost equation of the thermal generating units and is given by

$$
\min \quad F=\sum_{j=1}^{N_{g}} F_{j}\left(P_{j}\right)=\sum_{j=1}^{N_{g}}\left(a_{j}+b_{j} P_{j}+c_{j} P_{j}^{2}\right),
$$

where $N_{g}$ is the total number of generating units or generators, $F_{j}\left(P_{j}\right)$ is the cost function of the $j$ th generating unit ( $\$ / \mathrm{hr}), P_{j}$ is the real output of the $j$ th generating units (in MW), and $a_{j}, b_{j}$, and $c_{j}$ are fuel cost coefficients of the $j$ th generator.

In some ED problems, the admission valves control the steam entering the turbine through separate nozzle groups. When the valve opens, the fuel cost will increase dramatically because of the wire drawing effect, and this makes the practical objective function have many nondifferentiable points [44]. Therefore, the fuel cost function often contains many nonsmooth ripple curves due to the presence of valve-point effects. The objective function when the valve-point effect is taken into account is represented as

$$
\begin{aligned}
\min F= & \sum_{j=1}^{N_{g}} F_{j}\left(P_{j}\right)=\sum_{j=1}^{N_{g}}\left(a_{j}+b_{j} P_{j}+c_{j} P_{j}^{2}\right) \\
& +\left|e_{j} \sin \left(f_{j}\left(P_{j}^{\min }-P_{j}\right)\right)\right|,
\end{aligned}
$$

where $e_{j}$ and $f_{j}$ are nonsmooth fuel cost coefficients of the $j$ th generator with valve-point effects and $P_{j}^{\min }$ is the minimum power generation limit of the $j$ th generator (in MW).

\subsection{Optimization Constraints}

2.2.1. Power Balance Constraint. The total generated power should be equal to the sum of the total system demand $\left(P_{D}\right)$ and the total transmission network loss $\left(P_{L}\right)$ :

$$
\sum_{j=1}^{N_{g}} P_{j}=P_{D}+P_{L}
$$

The $B$ coefficient method is widely utilized to calculate the total transmission network loss $P_{L}$. In such a way, $P_{L}$ can be calculated as follows:

$$
P_{L}=\sum_{j=1}^{N_{g}} \sum_{i=1}^{N_{g}} P_{j} B_{j i} P_{i}+\sum_{j=1}^{N_{g}} B_{0 j} P_{i}+B_{00},
$$

where $B_{j i}, B_{j 0}$, and $B_{00}$ are the loss coefficients or $B$ coefficients. It can be seen that $\left[\mathbf{B}_{j i}\right]$ is an $N_{g} \times N_{\mathrm{g}}$ matrix.

2.2.2. Power Generation Limits. The power generation of each generator should be within its minimum and maximum limits:

$$
P_{j}^{\min } \leq P_{j} \leq P_{j}^{\max },
$$




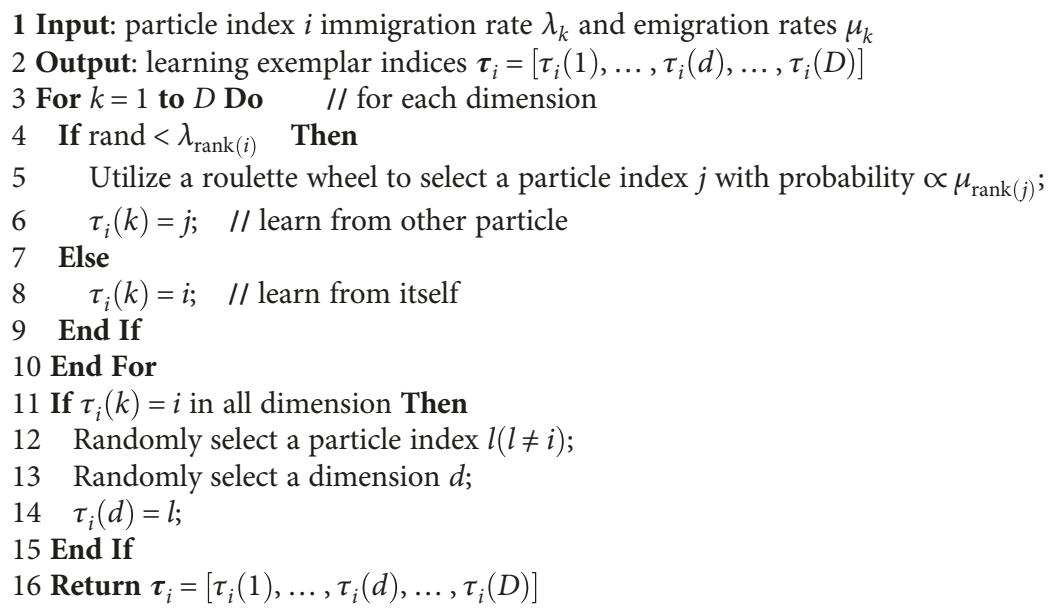

Algorithm 1: (biogeography-based exemplar generation method).

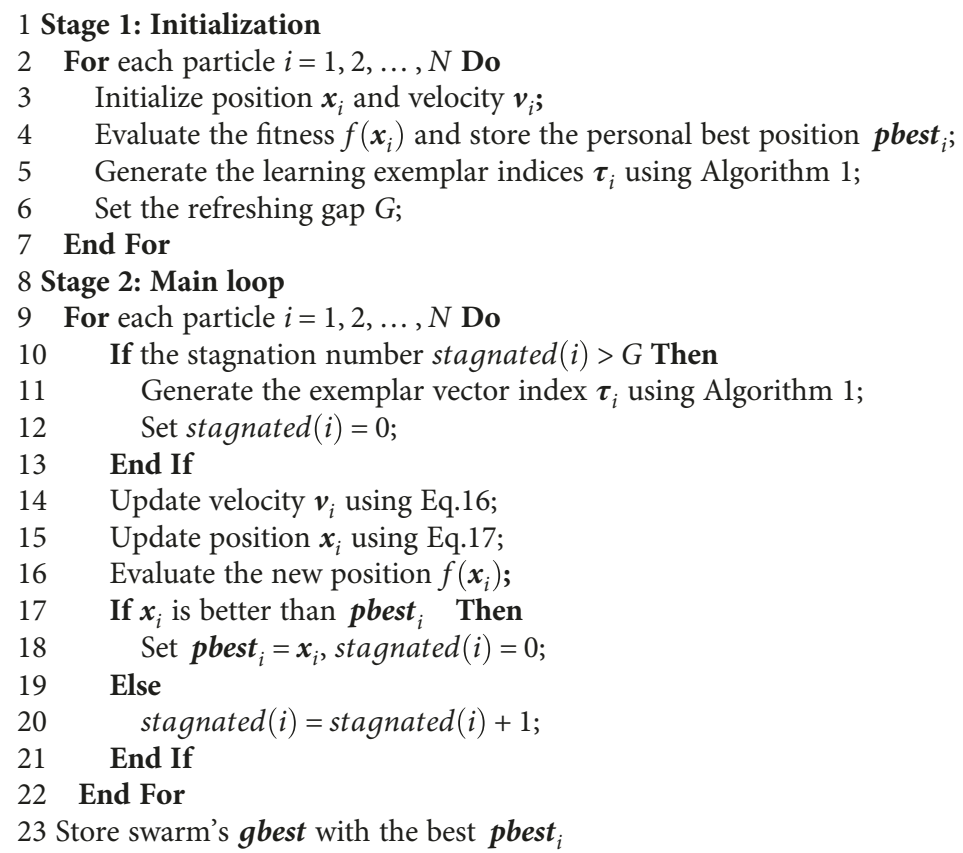

Algorithm 2: (BLPSO).

where $P_{j}^{\min }$ and $P_{j}^{\max }$ are the minimum and maximum power generation limits of the $j$ th generator.

2.2.3. Ramp-Rate Limits. The physical limitations of starting up and shutting down of generators impose ramp-rate limits, which are modeled as follows. The increase in generation is limited by

$$
P_{j}-P_{j}^{0} \leq \mathrm{UR}_{j}
$$

Similarly, the decrease is limited by

$$
P_{j}^{0}-P_{j} \leq \mathrm{DR}_{j},
$$

where $P_{j}^{0}$ is the previous output power and $U R_{j}$ and $D R_{j}$ are the up-ramp limit and the down-ramp limit of the $j$ th generator, respectively.

Combining 6 and 7 with 5 results in the change of the effective operating or generation limits to

$$
\max \left(P_{j}^{\min }, P_{j}^{0}-D R_{j}\right) \leq P_{j} \leq \min \left(P_{j}^{\max }, P_{j}^{0}+U R_{j}\right) .
$$

2.2.4. Prohibited Operating Zones. The prohibited operating zones (POZ) are due to steam valve operation or vibration 


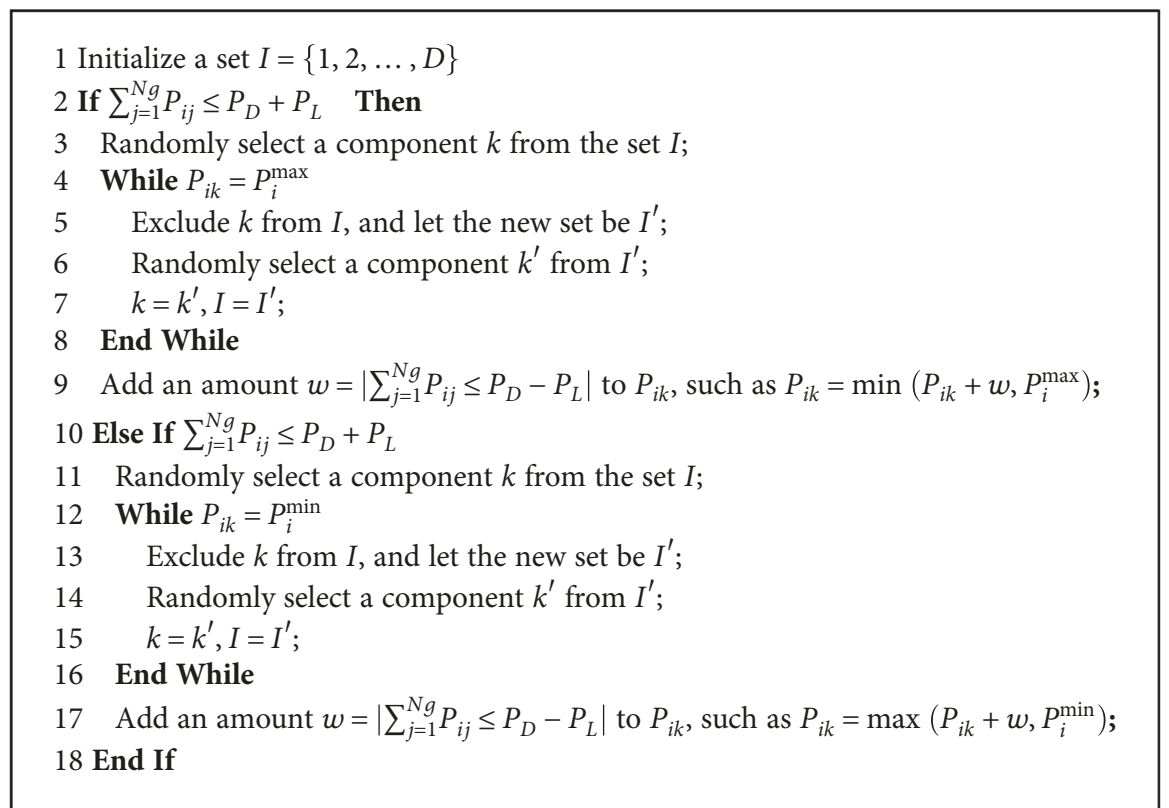

Algorithm 3: (the repair operator for power balance constraint).

in shaft bearing. The feasible operating zones of the $j$ th generator can be described as follows:

$$
P_{j} \in\left\{\begin{array}{l}
P_{j}^{\min } \leq P_{j} \leq P_{j, 1}^{l}, \\
P_{j, k-1}^{u} \leq P_{j} \leq P_{j, k}^{l}, \\
P_{j, n_{j}-1}^{u} \leq P_{j} \leq P_{j}^{\max }, \\
k=2,3, \ldots, n_{j}, j=1,2, \ldots, N_{g},
\end{array}\right.
$$

where $n_{j}$ is the number of prohibited zones of the $j$ th generator. $P_{j, k}^{l}$ and $P_{j, k}^{u}$ are the lower and upper power output of the $k$ th prohibited zone of the $j$ th generator, respectively.

Combining the equations from 2 to 9 , the ED problem can be formulated as

$$
\begin{gathered}
\min \quad F=\sum_{j=1}^{N_{g}} F_{j}\left(P_{j}\right)=\sum_{j=1}^{N_{g}}\left(a_{j}+b_{j} P_{j}+c_{j} P_{j}^{2}\right) \\
\quad+\left|e_{j} \sin \left(f_{j}\left(P_{j}^{\min }-P_{j}\right)\right)\right|, \\
\text { s.t. } \quad \sum_{j=1}^{N_{g}} P_{j}=P_{D}+P_{L}, \\
\max \quad\left(P_{j}^{\min }, P_{j}^{0}-D R_{j}\right) \leq P_{j} \leq P_{j, 1}^{l}, \\
\quad P_{j, k-1}^{u} \leq P_{j} \leq P_{j, k}^{l}, \\
\quad P_{j, k-1}^{u} \leq P_{j} \leq \min \left(P_{j}^{\max }, P_{j}^{0}+U R_{j}\right), \\
k=2,3, \ldots, n_{j}, j=1,2, \ldots, N_{g} .
\end{gathered}
$$

\section{Particle Swarm Optimization and Its Three Variants}

3.1. Particle Swarm Optimization. The PSO algorithm is a population-based metaheuristic algorithm which was firstly proposed by Eberhart and Kennedy [45]. It is based on the swarm intelligence theory, and the fundamental idea is that the optimal solution can be found through cooperation and information sharing among individuals in the swarm. In the past decade, PSO has gained increasing popularity due to its effectiveness in performing difficult optimization tasks.

In PSO, each individual is treated as a particle in the $D$-dimensional space, with a position vector $\mathbf{x}_{i}(t)=\left[x_{i 1}(t)\right.$, $\left.x_{i 2}(t), \ldots, x_{i D}(t)\right]$ and a velocity vector $\mathbf{v}_{i}(t)=\left[v_{i 1}(t), v_{i 2}(t)\right.$, $\left.\ldots, v_{i D}(t)\right]$. The particle updates its velocity and position according to the following equations:

$$
\begin{aligned}
v_{i j}(t+1)= & w v_{i j}(t)+c_{1} r_{1}\left(\text { pbest }_{i j}(t)-x_{i j}(t)\right) \\
& +c_{2} r_{2}\left(\text { gbest }_{j}(t)-x_{i j}(t)\right), \\
x_{i j}(t+1)= & x_{i j}(t)+v_{i j}(t),
\end{aligned}
$$

where $\operatorname{pbest}_{i}(t)=\left[\operatorname{pbest}_{i 1}(t)\right.$ pbest $_{i 2}(t), \ldots$, pbest $\left._{i D}(t)\right]$ is the personal best position of particle $i$; gbest $(t)=\left[\right.$ gbest $_{1}(t)$, gbe $\mathrm{st}_{2}(t), \ldots$, gbest $\left._{D}(t)\right]$ is the position of the best particle in the population; $w$ is the inertia weight; $c_{1}$ and $c_{2}$ are acceleration coefficients; and $r_{1}$ and $r_{2}$ are two random real numbers distributed uniformly within $[0,1]$.

3.2. Comprehensive Learning Particle Swarm Optimization. Liang et al. [46] proposed a comprehensive learning PSO (CLPSO) which uses a novel comprehensive learning strategy whereby all other particle personal best positions are used to update a particle velocity. This strategy can preserve the diversity of the swarm to discourage premature convergence. CLPSO uses the following velocity updating equation:

$$
v_{i j}(t+1)=w v_{i j}(t)+c r_{1}\left(\text { pbest }_{\tau_{i}(j), j}(t)-x_{i j}(t)\right) \text {, }
$$


TABLE 1: Table of abbreviations.

\begin{tabular}{|c|}
\hline Optimization algorithms \\
\hline Backtracking search algorithm \\
\hline Biogeography-based optimization \\
\hline Chaotic bat algorithm \\
\hline Chaotic improved honey bee mating optimization \\
\hline Continuous quick group search optimizer \\
\hline Differential evolution \\
\hline Enhanced Hopfield neural network \\
\hline Firefly algorithm \\
\hline Genetic algorithm-ant colony optimization \\
\hline Group search optimizer \\
\hline Honey bee mating optimization \\
\hline $\begin{array}{l}\text { Hybrid chemical reaction optimization } \\
\text { with differential evolution }\end{array}$ \\
\hline $\begin{array}{l}\text { Hybrid differential evolution with } \\
\text { biogeography-based optimization }\end{array}$ \\
\hline Harmony search \\
\hline Hopfield modeling framework \\
\hline Hybrid harmony search \\
\hline $\begin{array}{l}\text { Hybrid differential evolution with } \\
\text { biogeography-based optimization }\end{array}$ \\
\hline $\begin{array}{l}\text { Hybrid differential evolution with particle } \\
\text { swarm optimization }\end{array}$ \\
\hline Immune algorithm \\
\hline Improved differential evolution \\
\hline $\begin{array}{l}\text { Improved orthogonal design particle swarm } \\
\text { optimization-global version }\end{array}$ \\
\hline $\begin{array}{l}\text { Improved orthogonal design particle swarm } \\
\text { optimization-local version }\end{array}$ \\
\hline Improved random drift particle swarm optimization \\
\hline Modified artificial bee colony \\
\hline Multiple tabu search \\
\hline $\begin{array}{l}\text { Multistrategy ensemble biogeography-based } \\
\text { optimization }\end{array}$ \\
\hline New particle swarm optimization \\
\hline $\begin{array}{l}\text { New particle swarm optimization } \\
\text { with local random search }\end{array}$ \\
\hline Oppositional invasive weed optimization \\
\hline $\begin{array}{l}\text { Oppositional real-coded chemical reaction } \\
\text { optimization }\end{array}$ \\
\hline Particle swarm optimization \\
\hline $\begin{array}{l}\text { Particle swarm optimization with chaotic } \\
\text { sequences and crossover operator }\end{array}$ \\
\hline $\begin{array}{l}\text { Particle swarm optimization with } \\
\text { time-varying acceleration coefficients }\end{array}$ \\
\hline Random drift particle swarm optimization \\
\hline $\begin{array}{l}\text { Self-tuning improved random drift particle } \\
\text { swarm optimization }\end{array}$ \\
\hline Simulated annealing \\
\hline $\begin{array}{l}\text { Stochastic weight trade-off particle swarm } \\
\text { optimization }\end{array}$ \\
\hline
\end{tabular}

Tabu search
TABLE 2: Optimal generations and cost obtained by BLPSO for test system 1 (6-unit system, $P_{D}=1263 \mathrm{MW}$ ).

\begin{tabular}{|c|c|c|c|c|}
\hline Unit & $P_{j}^{\min }$ & $P_{j}^{\max }$ & POZ & Generation \\
\hline 1 & 100 & 500 & $\begin{array}{c}(210,240) ; \\
(350,380)\end{array}$ & 447.0682 \\
\hline 2 & 50 & 200 & $\begin{array}{l}(90,110) \\
(140,160)\end{array}$ & 173.5899 \\
\hline 3 & 80 & 300 & $\begin{array}{c}(150,170) \\
(210,240)\end{array}$ & 263.2341 \\
\hline 4 & 50 & 150 & $\begin{array}{c}(80,90) ; \\
(110,120)\end{array}$ & 142.6879 \\
\hline 5 & 50 & 200 & $\begin{array}{l}(90,110) \\
(140,150)\end{array}$ & 162.5776 \\
\hline 6 & 50 & 120 & $\begin{array}{c}(75,85) \\
(100,105)\end{array}$ & 86.5033 \\
\hline Cost $(\$ / \mathrm{hr})$ & & & 15447.34 & \\
\hline Transmission loss (MW) & & & 12.6619 & \\
\hline
\end{tabular}

HS

$\mathrm{HM}$

HHS

$\mathrm{DE} / \mathrm{BBO}$

DEPSO

IA

IDE

IODPSO-L

IODPSO-G

IRDPSO

MABC

MTS

MsEBBO

New-PSO

NPSO-LRS

OIWO

ORCCRO

PSO

CCPSO

PSO-TVAC

where pbest $_{\tau_{i}}(t)=\left[\right.$ pbest $_{\tau_{i}(1), 1}(t)$, pbest $\tau_{\tau_{i}(2), 2}(t), \ldots$, pbest $_{\tau_{i}}$ $\left.{ }_{(D), D}(t)\right]$ is the learning exemplar for particle $i$ and $\tau_{i}=$ $\left[\tau_{i}(1), \tau_{i}(2), \ldots, \tau_{i}(D)\right]$ is the learning exemplar indices for particle $i$, which is generated based on tournament selection procedure. The CLPSO does not introduce any complex operations to the original simple PSO framework, and the main difference from the original PSO is the velocity update equation.

3.3. Social Leaning Particle Swarm Optimization. Cheng and Jin [47] proposed a social learning PSO (SLPSO) inspired by learning mechanisms in social learning of animals. The SLPSO is performed on a sorted swarm, and particles learn from any better particles in the current swarm. The particles learn from different particles based on the following equations:

$$
\begin{aligned}
x_{i j}(t+1)= & \left\{\begin{array}{l}
x_{i j}(t)+\Delta x_{i j}(t) \text { if } p_{i}(t) \leq P_{i}^{L}, \\
x_{i j}(t), \quad \text { otherwise, }
\end{array}\right. \\
\Delta x_{i j}(t+1)= & r_{1} \Delta x_{i j}(t)+r_{2}\left(x_{k j}(t)-x_{i j}(t)\right) \\
& +r_{3} \varepsilon\left(\bar{x}_{j}(t)-x_{i j}(t)\right),
\end{aligned}
$$

where $P_{i}^{L}$ is the learning probability for particle $i, p_{i}(t)$ is a randomly generated probability that satisfies $0 \leq p_{i}(t) \leq$ $P_{i}^{L} \leq 1, x_{k j}(t)$ is the demonstrator of particle $i$ in the $j$ th dimension, $\bar{x}_{j}(t)=\sum_{i=1}^{N} x_{i j} / N$ is the mean position of the all particles in the current swarm, and $\varepsilon$ is the social influence factor. In addition, the SLPSO adopts dimension-dependent RDPSO parameter control methods to determine the three parameters, that is, the swarm size $N, P_{i}^{L}$ the learning probability, and the social influence factor $\varepsilon$.
3.4. Biogeography-Based Learning Particle Swarm Optimization. In this paper, a biogeography-based learning particle swarm optimization (BLPSO) which employs a new biogeography-based learning strategy (BLS) [48] is proposed for the ED problems. 
TABLE 3: Comparison of fuel costs and statistical results for test system 1 (6-unit system, $P_{D}=1263 \mathrm{MW}$ ).

\begin{tabular}{|c|c|c|c|c|c|}
\hline Algorithm & Minimum cost $(\$ / \mathrm{h})$ & Mean cost $(\$ / h)$ & Maximum cost $(\$ / h)$ & Standard deviation & Time (s) \\
\hline NPSO-LRS [54] & 15,450 & 15,454 & 15,452 & NA & NA \\
\hline MTS [55] & 15450.06 & 15451.17 & 15450.06 & 0.9287 & 1.29 \\
\hline TS [55] & 5454.89 & 15472.56 & 15454.89 & 13.7195 & 20.55 \\
\hline SA [55] & 15461.1 & 15488.98 & 15461.1 & 28.3678 & 50.36 \\
\hline GAAPI [56] & 15449.78 & 15449.81 & 15449.85 & NA & NA \\
\hline HCRO-DE [42] & 15443.075 & 15443.327 & 15443.916 & 0.067 & 4.17 \\
\hline $\mathrm{DE}[57]$ & 15449.5826 & 15449.62 & 15449.6508 & NA & 3.634 \\
\hline MABC [31] & 15449.8995 & 15449.8995 & 15449.8995 & $6.04 \mathrm{E}-08$ & 0.62 \\
\hline CBA [58] & 15450.2381 & 15454.76 & 15518.6588 & 2.965 & 0.704 \\
\hline RDPSO [26] & 15449.89 & 15458.01 & NA & 13.647 & 0.707 \\
\hline IRDPSO [26] & 15449.89 & 15456.55 & NA & 10.9865 & 0.676 \\
\hline ST-IRDPSO [26] & 15449.89 & 15450.7 & NA & 1.416 & 0.727 \\
\hline CLPSO & 15447.72 & 15449.83 & 15452.88 & 1.28 & 0.48 \\
\hline SLPSO & 15447.34 & 15447.46 & 15447.62 & 0.08 & 0.84 \\
\hline BLPSO & 15447.34 & 15447.45 & 15447.67 & 0.09 & 0.50 \\
\hline
\end{tabular}

NA means the data are not available in the literature.

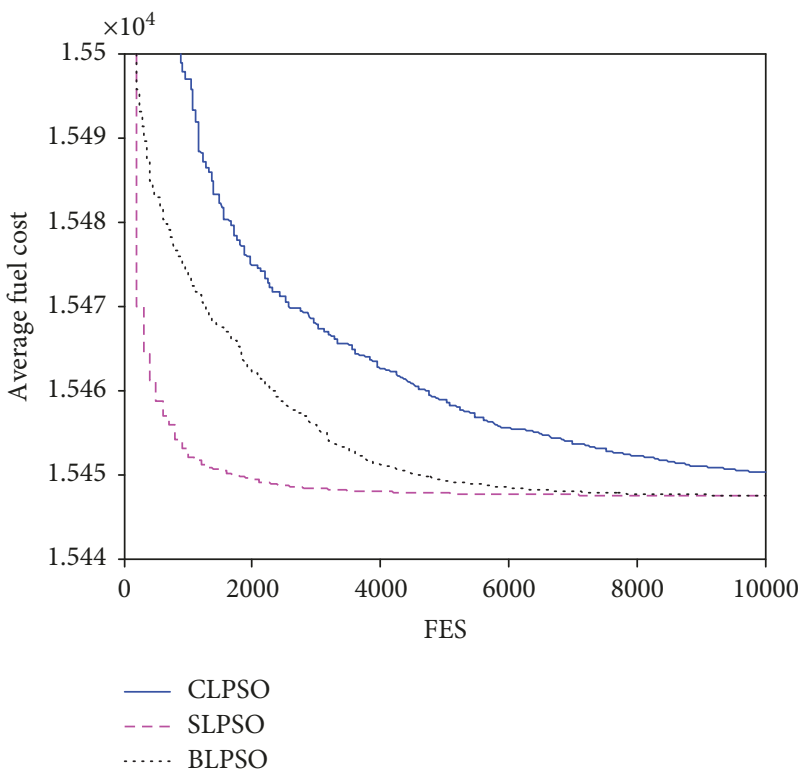

FIgURE 1: Convergence characteristics for test system 1.

3.4.1. Biogeography-Based Learning Strategy. BLS is inspired from both from the comprehensive learning strategy of CLPSO [46] and biogeography-based optimization $[49,50]$. It has two characteristics:

(1) Each particle updates itself by using the combination of its own personal best position and personal best positions of all other particles, which is similar to the comprehensive learning strategy of CLPSO. This updating method enables the diversity of the swarm to be preserved to discourage premature convergence.
TABLE 4: Optimal generations and cost obtained by BLPSO for test system 2 (15-unit system, $\left.P_{D}=2630 \mathrm{MW}\right)$.

\begin{tabular}{lccc}
\hline Unit & $P_{j}^{\min }$ & $P_{j}^{\max }$ & Generation \\
\hline 1 & 150 & 455 & 455.0000 \\
2 & 150 & 455 & 450.0000 \\
3 & 20 & 130 & 130.0000 \\
4 & 20 & 130 & 130.0000 \\
5 & 150 & 470 & 200.0000 \\
6 & 135 & 460 & 460.0000 \\
7 & 135 & 465 & 430.0000 \\
8 & 60 & 300 & 60.0000 \\
9 & 25 & 162 & 35.1998 \\
10 & 25 & 160 & 91.2383 \\
11 & 20 & 80 & 80.0000 \\
12 & 20 & 80 & 80.0000 \\
13 & 25 & 85 & 25.0000 \\
14 & 15 & 55 & 15.0000 \\
15 & 15 & 55 & 15.0000 \\
\hline Cost (\$/hr) & & 32587.33 \\
Transmission loss (MW) & \multicolumn{3}{|c}{} \\
\hline
\end{tabular}

(2) The migration operator of biogeography-based optimization is used to generate the learning exemplar for each particle, in which a ranking technique is employed to make particles learn more from particles with high-quality personal best positions. This can provide a more effecient balance between exploration and exploitation for the new PSO algorithm.

In BLS, each particle updates its velocity and position according to the following equations: 
TABle 5: Comparison of fuel costs and statistical results for test system 2 (15-unit system, $P_{D}=2630 \mathrm{MW}$ ).

\begin{tabular}{|c|c|c|c|c|c|}
\hline Algorithm & Minimum cost $(\$ / \mathrm{h})$ & Mean cost $(\$ / h)$ & Maximum cost $(\$ / \mathrm{h})$ & Standard deviation & Time (s) \\
\hline CCPSO [60] & 32704.4514 & 32704.4514 & 32704.4514 & 0 & 16.2 \\
\hline HBMO [59] & 32637.6219 & 32663.19 & 32676.07 & NA & 2.8 \\
\hline CIHBMO [59] & 32548.58588 & 32548.58588 & 32548.58588 & NA & 3.1 \\
\hline FA [15] & $32,704.50$ & $32,856.10$ & $33,175.00$ & 147.17 & NA \\
\hline MsEBBO [35] & $32,692.40$ & $32,692.40$ & $32,692.40$ & 0 & NA \\
\hline DEPSO [40] & 32588.81 & 32588.99 & 32591.49 & 4.02 & $1.88 \mathrm{~s}$ \\
\hline SWT-PSO [61] & 32704.45 & NA & NA & NA & NA \\
\hline IA [62] & $32,698.20$ & $32,750.22$ & $32,823.78$ & 9.3 & NA \\
\hline IODPSO-G [63] & $32,692.39$ & $32,692.39$ & $32,692.39$ & NA & NA \\
\hline IODPSO-L [63] & $32,692.39$ & $32,692.39$ & $32,692.39$ & NA & NA \\
\hline CLPSO & 32608.83 & 32649.9 & 32705.5 & 23.13 & 2.77 \\
\hline SLPSO & 32674.25 & 32707.46 & 32758.69 & 14.67 & 4.93 \\
\hline BLPSO & 32587.33 & 32607.17 & 32667.2 & 17.06 & 2.85 \\
\hline
\end{tabular}

NA means the data are not available in the literature.

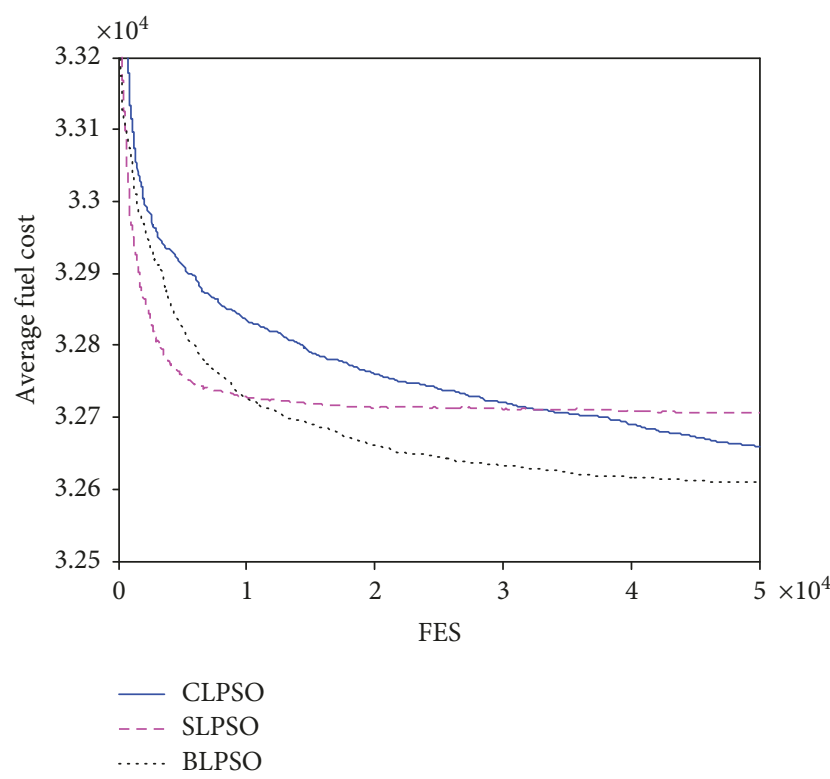

FIGURE 2: Convergence characteristics for test system 2.

$$
\begin{aligned}
& v_{i j}(t+) 1=w v_{i j}(t)+c r_{1}\left(\operatorname{pbest}_{\tau_{i}(j), j}(t)-x_{i j}(t)\right), \\
& x_{i j}(t+1)=x_{i j}(t)+v_{i j}(t),
\end{aligned}
$$

where pbest $_{\tau_{i}}(t)=\left[\right.$ pbest $_{\tau_{i}(1), 1}(t)$ pbest $_{\tau_{i}(2), 2}(t), \ldots$, pbest $_{\tau_{i}}$ $(D), D(t)]$ is the learning exemplar for particle $i ; \tau_{i}=\left[\tau_{i}(1)\right.$, $\left.\tau_{i}(2), \ldots, \tau_{i}(D)\right]$ is the learning exemplar indices for particle $i$, which is generated by the biogeographic migration.

In the biogeographic migration, all particles are firstly sorted based on the value of their pbest from best to worst and assigned with ranking values. For a minimization problem, assume

$$
f\left(\text { pbest }_{s_{1}}\right) \leq f\left(\text { pbest }_{s_{2}}\right) \leq \cdots \leq f\left(\text { pbest }_{s_{N}}\right),
$$

\begin{tabular}{|c|c|c|c|}
\hline Unit & $P_{j}^{\min }$ & $P_{j}^{\max }$ & Generation \\
\hline 1 & 150 & 600 & 512.2358 \\
\hline 2 & 50 & 200 & 169.7731 \\
\hline 3 & 50 & 200 & 126.4272 \\
\hline 4 & 50 & 200 & 102.6131 \\
\hline 5 & 50 & 160 & 113.9049 \\
\hline 6 & 20 & 100 & 73.6208 \\
\hline 7 & 25 & 125 & 115.506 \\
\hline 8 & 50 & 150 & 116.631 \\
\hline 9 & 50 & 200 & 100.2842 \\
\hline 10 & 30 & 150 & 105.5532 \\
\hline 11 & 100 & 300 & 150.2329 \\
\hline 12 & 150 & 500 & 293.3209 \\
\hline 13 & 40 & 160 & 118.8701 \\
\hline 14 & 20 & 130 & 30.6567 \\
\hline 15 & 25 & 185 & 115.3421 \\
\hline 16 & 20 & 80 & 36.2973 \\
\hline 17 & 30 & 85 & 67.0567 \\
\hline 18 & 30 & 120 & 87.9775 \\
\hline 19 & 40 & 120 & 101.2398 \\
\hline 20 & 30 & 100 & 54.4584 \\
\hline Cost $(\$ / h r)$ & \multicolumn{3}{|c|}{62456.58} \\
\hline Transmission loss (MW) & \multicolumn{3}{|c|}{92.0046} \\
\hline
\end{tabular}

TABLE 6: Optimal generations and cost obtained by the BLPSO for test system 3 (20-unit system, $P_{D}=2500 \mathrm{MW}$ ).

where $s_{1}$ is the subscript of the particle with the best pbest, $s_{2}$ is the subscript of the particle with the second best pbest, and $s_{N}$ is the subscript of the particle with the worst pbest; $N$ is the population size. Then, the rankings of particles are assigned as below:

$$
\operatorname{rank}\left(\mathbf{x}_{s k}\right)=N-k, \quad k=1,2, \ldots, N .
$$


TABLe 7: Comparison of fuel costs and statistical results for test system 3 (20-unit system, $P_{D}=2500 \mathrm{MW}$ ).

\begin{tabular}{|c|c|c|c|c|c|}
\hline Algorithm & Minimum cost $(\$ / h)$ & Mean cost $(\$ / h)$ & Maximum cost $(\$ / \mathrm{h})$ & Standard deviation & Time (s) \\
\hline EHNN [65] & 62,610 & NA & NA & NA & 0.11 \\
\hline$\lambda$-iteration $[64]$ & 62456.6391 & NA & NA & NA & 33.757 \\
\hline HM [64] & 62456.6341 & NA & NA & NA & 6.355 \\
\hline GSO [66] & 62456.6332 & 62456.6336 & 62456.6353 & NA & 30.45 \\
\hline CQGSO [66] & 62456.633 & 62456.6331 & 62456.63337 & NA & 11.13 \\
\hline $\mathrm{BBO}[22]$ & 62456.7793 & 62456.7928 & 62456.7928 & NA & NA \\
\hline BSA [22] & 62456.6925 & 62457.1517 & 62458.1272 & NA & 14.477 \\
\hline CBA [58] & 62456.6328 & 62456.6348 & 62501.6714 & 0.3879 & 1.16 \\
\hline CLPSO & 62456.44 & 62456.84 & 62457.10 & 0.17 & 2.68 \\
\hline SLPSO & 62456.92 & 62457.38 & 62458.06 & 0.28 & 3.80 \\
\hline BLPSO & 62456.58 & 62456.64 & 62456.65 & 0.01 & 2.75 \\
\hline
\end{tabular}

NA means the data are not available in the literature.

Second, immigration and emigration rates are assigned for all particles. The immigration and emigration rates for all particles can be calculated as follows:

$$
\begin{aligned}
\lambda\left(\mathbf{x}_{s_{k}}\right) & =\left(1-\frac{N-k}{N}\right)^{2}, \\
\mu\left(\mathbf{x}_{s_{k}}\right) & =\left(\frac{N-k}{N}\right)^{2}, \\
& k=1,2, \ldots, N .
\end{aligned}
$$

According to 20, the solution $\mathbf{x}_{s_{1}}$ with the best pbest ${ }_{s_{1}}$ will have the lowest immigration rate and highest emigration rate; and the solution $\mathbf{x}_{s_{N}}$ with the worst pbest $s_{s_{N}}$ will have the highest immigration rate and lowest emigration rate.

Third, the biogeography-based exemplar indices $\boldsymbol{\tau}_{i}=$ $\left[\tau_{i}(1), \tau_{i}(2), \ldots, \tau_{i}(D)\right]$ for particle $i$ can be generated based on the biogeography-based exemplar generation method, see Algorithm 1.

3.4.2. Procedures of BLPSO. Using the BLS, the procedures of BLPSO can be outlined in Algorithm 2. It can be seen from Algorithm 2 that the structure of BLPSO is as simple as the classic PSO.

In addition, based on lines 10-13 in Algorithm 2, it can be seen that Algorithm 1 is executed to generate new learning exemplar indices $\boldsymbol{\tau}_{i}$ only when there is a stagnation for $G$ generations, which is used to save computational cost of the BLPSO. In other words, if new learning exemplar indices $\tau_{i}$ are generated for all particles in each generation, Algorithm 2 will be executed too frequently, and this may cost a large computational time, which is inappropriate for real-world ED problems.

\subsubsection{Remarks}

(1) Complexity Analysis. The computational costs of the original BLPSO algorithm involve the initialization $\left(T_{\text {ini }}\right)$, biogeography-based exemplar generation method $\left(T_{\text {bio }}\right)$, velocity and position update $\left(T_{\text {upd }}\right)$, and evaluation $\left(T_{\text {eva }}\right)$ for each particle. Assume $D$ is the dimensionality of the

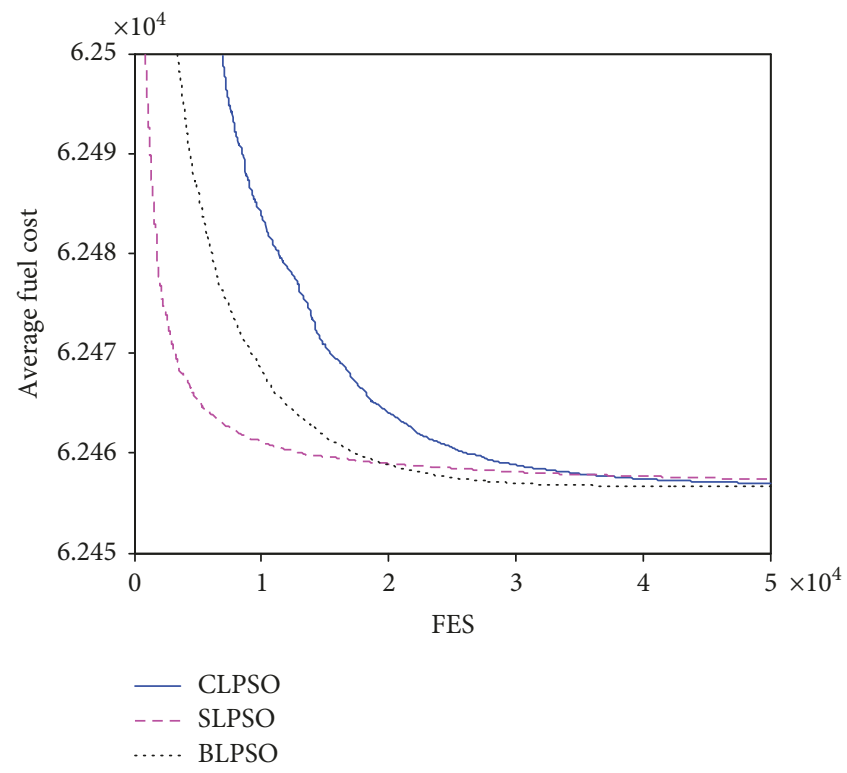

FIgURE 3: Convergence characteristics for test system 3.

optimization problem, $N$ is the population size, and maxF ES is maximum number of functional evaluations allowed for the algorithm. The complexity of initialization, velocity and position update, and evaluation are $O(D), O(2 D)$, and $O(D)$, respectively. The computational costs of biogeographybased exemplar generation method $T_{\text {bio }}$ include population sorting $O(N \cdot \log (N))$, ranking assignment $O(N)$, immigration and emigration rate assignment $O(2 N)$, and migration operator $O(N \cdot D)$. Therefore, $T_{\text {bio }}=O(N \cdot \log$ $(N))+O(N)+O(2 N)+O(N \cdot D)=O(3 N+N \cdot \log (N)+$ $N \cdot D)$.

The total computational complexity of BLPSO is $T_{\text {BLPSO }}=T_{\text {ini }}+\left(T_{\text {eva }}+T_{\text {upd }}+(1 / G) T_{\text {bio }}\right) \cdot \operatorname{maxFE}=O(D+$ $(D+2 D+((3 N+N \cdot \log (N)+N \cdot D) / G)) \cdot \operatorname{maxFES})$. In general, the population size $N$ is often set to be proportional to the problem dimension $D$ (i.e., $N=k D$ ) [47]. Thus, the complexity of BLPSO is $T_{\text {BLPSO }}=O(D+(D+2$ $\left.\left.D+\left(\left(3 k D+k D \cdot \log (k D)+k D^{2}\right) / G\right)\right) \cdot \operatorname{maxFES}\right)=O\left(D^{2}\right.$. maxFES). 
TABLE 8: Optimal generations and cost obtained by the BLPSO for test system 4 (38-unit system, $P_{D}=6000 \mathrm{MW}$ ).

\begin{tabular}{|c|c|c|c|}
\hline Unit & $P_{j}^{\min }$ & $P_{j}^{\max }$ & Generation \\
\hline 1 & 220 & 550 & 426.5025 \\
\hline 2 & 220 & 550 & 426.7865 \\
\hline 3 & 200 & 500 & 429.5064 \\
\hline 4 & 200 & 500 & 429.6401 \\
\hline 5 & 200 & 500 & 429.7661 \\
\hline 6 & 200 & 500 & 429.5265 \\
\hline 7 & 200 & 500 & 429.7083 \\
\hline 8 & 200 & 500 & 429.5542 \\
\hline 9 & 114 & 500 & 114 \\
\hline 10 & 114 & 500 & 114 \\
\hline 11 & 114 & 500 & 119.7279 \\
\hline 12 & 114 & 500 & 127.1661 \\
\hline 13 & 110 & 500 & 110 \\
\hline 14 & 90 & 365 & 90 \\
\hline 15 & 82 & 365 & 82 \\
\hline 16 & 120 & 325 & 120 \\
\hline 17 & 65 & 315 & 159.6378 \\
\hline 18 & 65 & 315 & 65 \\
\hline 19 & 65 & 315 & 65 \\
\hline 20 & 120 & 272 & 272 \\
\hline 21 & 120 & 272 & 272 \\
\hline 22 & 110 & 260 & 260 \\
\hline 23 & 80 & 190 & 130.682 \\
\hline 24 & 10 & 150 & 10 \\
\hline 25 & 60 & 125 & 113.3391 \\
\hline 26 & 55 & 110 & 88.0312 \\
\hline 27 & 35 & 75 & 37.5497 \\
\hline 28 & 20 & 70 & 20 \\
\hline 29 & 20 & 70 & 20 \\
\hline 30 & 20 & 70 & 20 \\
\hline 31 & 20 & 70 & 20 \\
\hline 32 & 20 & 60 & 20 \\
\hline 33 & 25 & 60 & 25 \\
\hline 34 & 18 & 60 & 18 \\
\hline 35 & 8 & 60 & 8 \\
\hline 36 & 25 & 60 & 25 \\
\hline 37 & 20 & 38 & 21.7594 \\
\hline 38 & 20 & 38 & 21.0902 \\
\hline Cost & \multicolumn{3}{|c|}{9417208.19} \\
\hline
\end{tabular}

(2) Compared with Previous Hybrid PSO/BBO Algorithms. Several hybrid $\mathrm{PSO} / \mathrm{BBO}$ algorithms have been proposed in the literature. For example, Guo et al. [51] presented a biogeography-based particle swarm optimization with fuzzy elitism (BPSO-FE) for constrained engineering problems. In this BPSO-FE algorithm, the whole population is split into several subgroups, and $\mathrm{BBO}$ is employed to search within each subgroup while PSO for the global search. Mo and Xu [52] applied the position updating strategy of PSO to increase the diversity of population in $\mathrm{BBO}$ and develop a biogeography particle swarm optimization algorithm (BPSO) to optimize the paths in path network. However, there are some differences between BLPSO and them. First, the hybrid strategies of BLPSO, BPSO-FE, and BPSO are different. In BLPSO, the biogeography-based migration is used to generate the learning exemplar for each particle; while in BPSO$\mathrm{FE}$ and BPSO, the biogeography-based migration is used as search operator. Second, the application areas of BLPSO, BPSO-FE, and BPSO are different. BLPSO is presented for ED problems, while BPSO-FE and BPSO are proposed for classical engineering optimization problems and robot path planning, respectively.

\section{Implementation of BLPSO for ED Problems}

When solving the ED problems using BLPSO, the following three important issues should be considered: initialization of population, constraint handling, and stopping criterion.

4.1. Initialization of Population. In BLPSO, each individual of the population is a solution of an ED problem. If there are $N_{g}$ units that must be operated to provide power to load, then the current position of the $i$ th particle can be given by

$$
X_{i}=\left[P_{i 1}, P_{i 2}, \ldots, P_{i j}, \ldots, P_{\mathrm{iN}_{g}}\right], \quad k=1,2, \ldots, N,
$$

where $N$ is the population size, $j$ is index of the generating unit, and $P_{i j}$ is the generation power output of the $j$ th generating unit in the $i$ th particle.

4.2. Constraint Handling. One of the most important issues in solving ED problems is how to handle the quality and inequality constraints. There are four types of constraints in the ELD problems: power generation limits, ramp-rate limits, prohibited operating zone, and power balance constraint.

For power generation limit and ramp-rate limit constraints, the following strategy is employed:

$$
P_{i j}=\left\{\begin{array}{l}
\max \left(P_{j}^{\min }, P_{j}^{0}-D R_{j}\right) \text { if } P_{i j} \leq \max \left(P_{j}^{\min }, P_{j}^{0}-D R_{j}\right), \\
\min \left(P_{j}^{\max }, P_{j}^{0}+U R_{j}\right) \text { if } P_{i j} \geq \min \left(P_{j}^{\max }, P_{j}^{0}+U R_{j}\right), \\
P_{i j}, \quad \text { otherwise. }
\end{array}\right.
$$

For prohibited operating zone constraints, if $P_{i j}$ is located in the $k$ th prohibited operating zone, that is, $P_{j, k}^{l} \leq P_{i j} \leq P_{j, k}^{u}$, it is truncated to the closest boundary of the $k$ th prohibited operating zone as follows:

$$
P_{i j}= \begin{cases}P_{j, k}^{l} & \text { if } P_{j, k}^{l}<P_{i j} \leq \frac{\left(P_{j, k}^{l}+P_{j, k}^{u}\right)}{2}, \\ P_{j, k}^{u} & \text { if } \frac{\left(P_{j, k}^{l}+P_{j, k}^{u}\right)}{2}<P_{i j}<P_{j, k}^{u}\end{cases}
$$


TABLE 9: Comparison of fuel costs and statistical results for test system 4 (38-unit system, $P_{D}=6000 \mathrm{MW}$ ).

\begin{tabular}{|c|c|c|c|c|c|}
\hline Algorithm & Minimum cost $(\$ / \mathrm{h})$ & Mean cost $(\$ / h)$ & Maximum cost $(\$ / h)$ & Standard deviation & Time (s) \\
\hline New-PSO [67] & 9516448.312 & NA & NA & NA & NA \\
\hline PSO-TVAC [67] & 9500448.307 & NA & NA & NA & NA \\
\hline HS [68] & $9,419,960$ & $9,421,056$ & $9,427,466$ & NA & 10.02 \\
\hline HHSÂ [68] & $9,417,325$ & $9,417,336$ & $9,417,466$ & NA & 5.06 \\
\hline BBOÂ [41] & 9417633.638 & NA & NA & NA & NA \\
\hline $\mathrm{DE} / \mathrm{BBO}[41]$ & 9417235.786 & NA & $\mathrm{NA}$ & NA & NA \\
\hline MsEBBO [35] & 9417235.776 & 9417235.779 & 9417235.778 & 0.0032 & NA \\
\hline IDE [28] & 9417235.786 & 9417235.786 & 9417235.786 & $6.00 \mathrm{E}-09$ & 9.149 \\
\hline CLPSO & 9418283.79 & 9419255.18 & 9420192.8 & 526.51 & 2.86 \\
\hline SLPSO & 9418407.11 & 9419560.62 & 9425492.54 & 1312.2 & 3.53 \\
\hline BLPSO & 9417208.19 & 9417234.16 & 9417235.9 & 5.23 & 2.89 \\
\hline
\end{tabular}

NA means the data are not available in the literature.

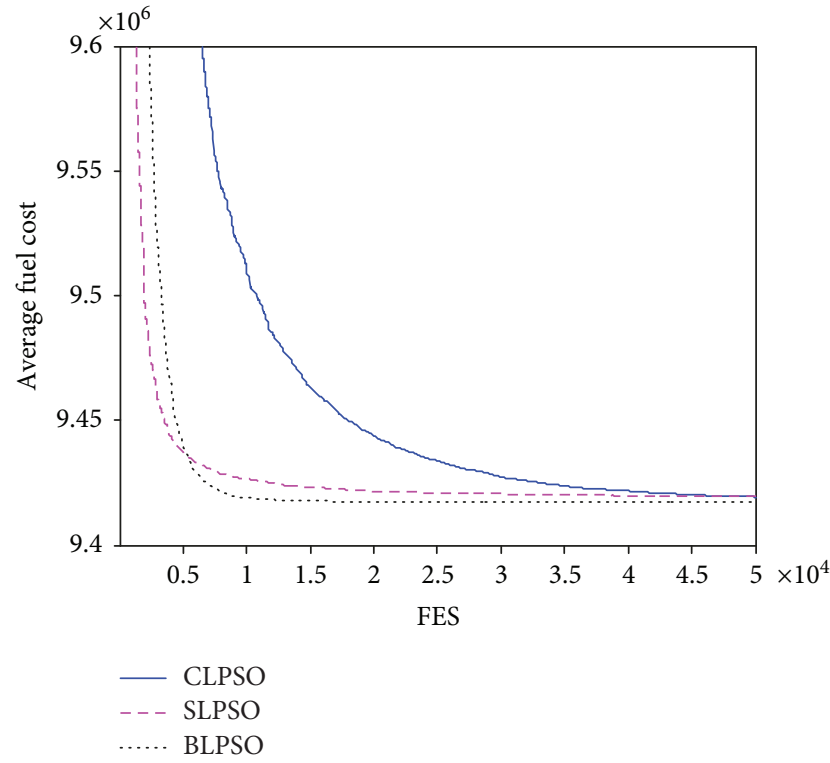

FIGURE 4: Convergence characteristics for test system 4.

where $P_{j, k}^{l}$ and $P_{j, k}^{u}$ denote the lower and the upper bounds of prohibited operation zone $k$ of generator $j$, respectively.

For the power balance constraint, a repaired operator together with a common penalty is employed [28]. The repaired operator is shown in Algorithm 3, and the objective function becomes

$$
\min \quad F=\sum_{j=1}^{N_{g}} F_{j}\left(P_{j}\right)+K\left|\sum_{j=1}^{N_{g}} P_{j}-P_{D}-P_{L}\right|,
$$

where $K$ is the penalty coefficient and the penalty term $\left|\sum_{j=1}^{N_{g}} P_{j}-P_{D}-P_{L}\right|$ is the measure of violation of the equality constraint.

4.3. Stopping Criterion. The BLPSO algorithm will be terminated if the maximum number of functional evaluations ma $\mathrm{xFES}$ is reached.

\section{Results and Discussion}

To test the effectiveness of the proposed BLPSO algorithm, five different test systems of varying computational difficulty levels have been solved using BLPSO. The results obtained by BLPSO are compared with two PSO algorithms, comprehensive learning PSO (CLPSO) [46] and social leaning PSO (SLPSO) [47]. The results are also compared with several techniques reported in the literature whose abbreviations are listed in Table 1.

To compare the performance of the BLPSO, 50 independent trial runs are made, and the statistical results including the minimum, mean, maximum fuel cost, and standard deviation, as well as average run time, are tabulated for each test system. The parameters of BLPSO are set as follows: population size $N=40$, inertia weight $w$ linearly decreases from 0.9 to 0.2 , acceleration coefficient $c=1.496$, and refreshing gap $G=5$. The parameters of CLPSO and SLPSO are set as those recommended in their original papers. The maximum number of functional evaluations maxFES is set as 10,000; 50,000; 50,000; 50,000; and 200,000 for the five test systems, respectively. The programs are implemented in MATLAB language on a personal computer with a $3.2 \mathrm{GHz}$ processor and $8 \mathrm{~GB}$ RAM.

5.1. Test System 1. This is a small system comprising 6 generators and meeting a load demand of $1263 \mathrm{MW}$ and includes transmission loss, POZ, and ramp-rate limits. The system data are taken from $[8,53]$ and listed in Table S1. Table 2 presents the optimal generation values and fuel cost obtained by BLPSO. The obtained optimal cost is 15447.34 $\$ /$ hr. It can be seen that the generation values satisfy the generation limit constraints and do not fall in the POZs.

Table 3 shows the comparison of the statistical results of different algorithms. In the table, the results obtained by BLPSO are compared with CLPSO, SLPSO, NPSO-LRS [54], MTS [55], TS [55], SA [55], GAAPI [56], HCRO-DE [42], DE [57], MABC [31], CBA [58], RDPSO [26], IRDPSO [26], and ST-IRDPSO [26]. It can be seen that the minimum and mean fuel costs obtained by BLPSO are similar to SLPSO and less than all the other methods with the exceptions of 
TABLe 10: Optimal generations and cost obtained by the CBA for test system 5 (110-unit system, $\left.P_{D}=5000 \mathrm{MW}\right)$.

\begin{tabular}{lccccccccc}
\hline Unit & Generation & Unit & Generation & Unit & Generation & Unit & Generation & Unit & Generation \\
\hline 1 & 2.4 & 23 & 68.9 & 45 & 660 & 67 & 70 & 89 & 82.7308 \\
2 & 2.4 & 24 & 350 & 46 & 616.4766 & 68 & 70 & 90 & 89.7172 \\
3 & 2.4 & 25 & 400 & 47 & 5.4 & 69 & 70 & 91 & 57.9161 \\
4 & 2.4 & 26 & 400 & 48 & 5.4 & 70 & 360 & 92 & 100 \\
5 & 2.4 & 27 & 500 & 49 & 8.4 & 71 & 400 & 93 & 440 \\
6 & 4 & 28 & 500 & 50 & 8.4 & 72 & 400 & 94 & 500 \\
7 & 4 & 29 & 200 & 51 & 8.4 & 73 & 105.0721 & 95 & 600 \\
8 & 4 & 30 & 100 & 52 & 12 & 74 & 190.995 & 96 & 471.2608 \\
9 & 4 & 31 & 10 & 53 & 12 & 75 & 90 & 97 & 3.6 \\
10 & 64.6059 & 32 & 20 & 54 & 12 & 76 & 50 & 98 & 3.6 \\
11 & 62.3474 & 33 & 80 & 55 & 12 & 77 & 160 & 99 & 4.4 \\
12 & 36.3769 & 34 & 250 & 56 & 25.2 & 78 & 295.3172 & 100 & 4.4 \\
13 & 56.6463 & 35 & 360 & 57 & 25.2 & 79 & 174.949 & 101 & 10 \\
14 & 25 & 36 & 400 & 58 & 35 & 80 & 98.2904 & 102 & 10 \\
15 & 25 & 37 & 40 & 59 & 35 & 81 & 10 & 103 & 20 \\
16 & 25 & 38 & 70 & 60 & 45 & 82 & 12 & 104 & 20 \\
17 & 155 & 39 & 100 & 61 & 45 & 83 & 20 & 105 & 40 \\
18 & 155 & 40 & 120 & 62 & 45 & 84 & 200 & 106 & 40 \\
19 & 155 & 41 & 156.791 & 63 & 185 & 85 & 325 & 107 & 50 \\
20 & 155 & 42 & 220 & 64 & 185 & 86 & 440 & 108 & 30 \\
21 & 68.9 & 43 & 440 & 65 & 185 & 87 & 13.9066 & 109 & 40 \\
22 & 68.9 & 44 & 560 & 66 & 185 & 88 & 24.4992 & 110 & 20 \\
\hline Cost (\$/hr) & & & & & 197988.16 & & & & \\
\hline & & & & & & & & & \\
\hline
\end{tabular}

HCRO-DE [42]. In addition, the smaller value of standard deviation indicates that BLPSO is consistent. It is also important to note that the BLPSO is very efficient according to the average computational time $(0.50 \mathrm{~s})$, which is less than most of other methods. Figure 1 presents the convergence characteristics obtained by CLPSO, SLPSO, and BLPSO. From Figure 1, SLPSO has the fastest convergence speed, and BLPSO has the second. Both BLPSO and SLPSO can converge to the optimal cost after about 6000 functional evaluations.

5.2. Test System 2. This test system consists of 15 generators meeting a load demand of $2630 \mathrm{MW}$ and includes transmission loss, POZ, and ramp-rate limits. The system data are taken from $[8,59]$ and listed in Table S2. Table 4 presents the optimal generations and the costs obtained. The optimal cost obtained by BLPSO is $32587.33 \$ / \mathrm{hr}$, and the generations satisfy the generation limit constraints.

Table 5 shows the comparison of the statistical results of the BLPSO and other algorithms, including CLPSO, SLPSO, CCPSO [60], HBMO [59], CIHBMO [59], FA [15], MsEBBO [35], DEPSO [40], SWT-PSO [61], IA [62], IODPSO-G [63], and IODPSO-L [63]. The minimum and mean fuel costs obtained by BLPSO are the least of all methods with the exceptions of HBMO [59]. The average computation time of BLPSO (2.85 s) is also very small. The convergence characteristics obtained by CLPSO, SLPSO, and BLPSO are plotted in Figure 2. SLPSO has the fastest convergence speed in the beginning, but it is surpassed by BLPSO and CLPSO in the end. Only BLPSO can get the optimal cost in this case.

5.3. Test System 3. This test system consists of 20 generators supplying a demand of $2500 \mathrm{MW}$. Transmission losses are included in this system. The cost coefficient and $B$ coefficient data are taken from $[22,64]$ and listed in Table S3. Table 6 presents the optimal generation values and fuel cost obtained by the BLPSO. The optimal obtained fuel cost is $62456.58 \$ / \mathrm{hr}$. It is seen that the all the generation limit constraints are satisfied.

Table 7 shows the comparison of the statistical results of different algorithms. In the table, the results obtained by BLPSO are compared with CLPSO, SLPSO, EHNN [65], $\lambda$-iteration [64], HM [64], GSO [66], CQGSO [66], BBO [22], BSA [22], and CBA [58]. It can be seen that the best fuel cost obtained by BLPSO is the least of all methods, and the mean fuel cost is the least of all methods with the sole exception of CBA [58]. In addition, the standard deviation and average computation time of BLPSO are both very small. Again, the BLPSO is efficient for this case. The convergence characteristics obtained by CLPSO, SLPSO, and BLPSO are plotted in Figure 3.

5.4. Test System 4. This test system consists of 38 generators, and the demand of this system is $6000 \mathrm{MW}$. The system data are taken from $[28,41]$ and listed in Table S4. Table 8 presents the optimal generation values and cost obtained by 
TABLE 11: Comparison of fuel costs and statistical results for test system 5 (110-unit system, $P_{D}=15,000 \mathrm{MW}$ ).

\begin{tabular}{|c|c|c|c|c|c|}
\hline Algorithm & Minimum cost $(\$ / \mathrm{h})$ & Mean cost $(\$ / h)$ & Maximum cost $(\$ / h)$ & Standard deviation & Time (s) \\
\hline SAB [71] & 206912.9057 & 207764.73 & NA & NA & NA \\
\hline SAF [71] & 207380.5164 & 207813.37 & NA & NA & NA \\
\hline SA [71] & 198352.6413 & 201595.19 & NA & NA & NA \\
\hline ORCCRO [72] & 198016.29 & 198016.32 & 198016.89 & NA & 0.15 \\
\hline $\mathrm{BBO}[72]$ & 198241.166 & 198413.45 & $199,102.59$ & NA & 115 \\
\hline $\mathrm{DE} / \mathrm{BBO}[72]$ & 198231.06 & 198326.66 & $198,828.57$ & NA & 132 \\
\hline OIWO [69] & 197989.14 & 197989.41 & 197989.93 & NA & 31 \\
\hline CLPSO & 198137.7 & 198200.37 & 198257.56 & 27.88 & 23.43 \\
\hline SLPSO & 198240.4 & 198351.62 & 198602.16 & 96 & 22.59 \\
\hline BLPSO & 197988.16 & 197988.18 & 197988.19 & 0 & 22.81 \\
\hline
\end{tabular}

NA means the data are not available in the literature.

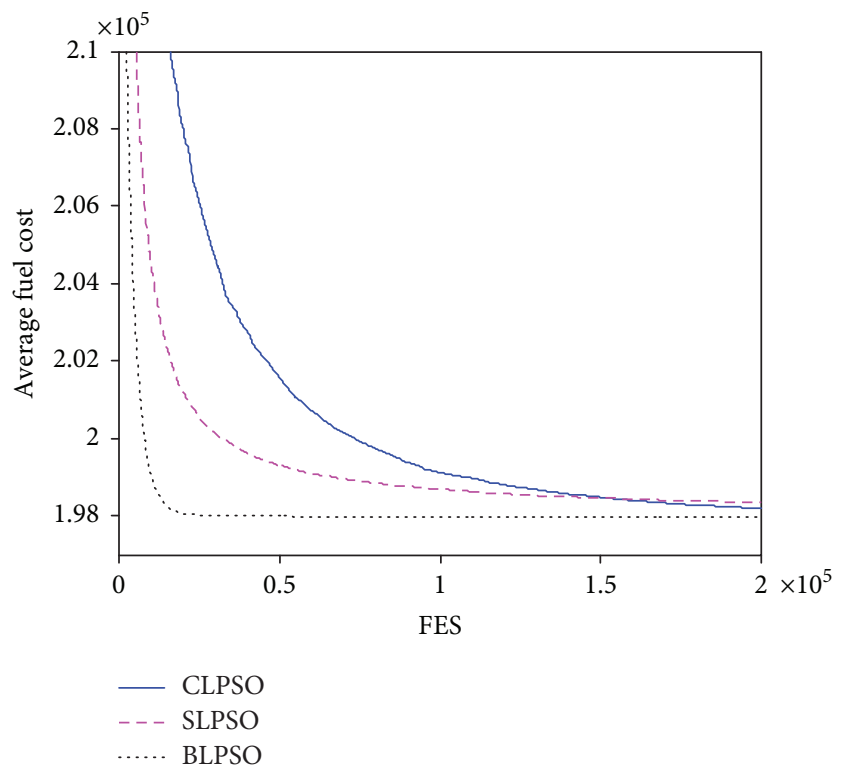

FIGURE 5: Convergence characteristics for test system 5.

BLPSO. The optimal cost is $9417208.19 \$ / \mathrm{hr}$. It is seen that the generations satisfy the generation limit constraints.

The results obtained by BLPSO are compared with those obtained by CLPSO, SLPSO, New-PSO [67], PSO-TVAC [67], HS [68], HHS [68], BBO [41], DE/BBO [41], MsEBBO [35], and IDE [28], as shown in Table 9. It can be seen that the minimum and mean fuel costs obtained by BLPSO are the least of all the methods. The average computation time of BLPSO is $2.89 \mathrm{~s}$, smaller than all methods, with the exception of CLPSO. The convergence characteristics obtained by CLPSO, SLPSO, and BLPSO are plotted in Figure 4.

5.5. Test System 5. In order to study the performance of the BLPSO on high-dimensional ED problems, a large system with 110 generators is considered. The demand of this system is $15,000 \mathrm{MW}$, and the system data are taken from $[69,70]$ and listed in Table S5. Table 10 presents the optimal generation values and cost obtained by BLPSO. The optimal cost is $197988.16 \$ / \mathrm{hr}$.
Table 11 shows the comparison of the statistical results of BLPSO and other algorithms, including CLPSO, SLPSO, SAB [71], SAF [71], SA [71], ORCCRO [72], BBO [72], DE/BBO [72], and OIWO [69]. The minimum, mean, and maximum fuel costs obtained by BLPSO are the least of all the methods. Meanwhile, the smaller value of standard deviation indicates that BLPSO is consistent. The average computation time of BLPSO is also very small compared with other methods. The convergence characteristics obtained by CLPSO, SLPSO, and BLPSO are presented in Figure 5.

\section{Conclusion}

This paper has presented a biogeography-based learning particle swarm optimization (BLPSO) for solving the economic dispatch (ED) problems, which is nonlinear, nonconvex, and discontinuous in nature, with numerous equality and inequality constraints. In the BLPSO, a biogeography-based learning strategy is used to generate the learning exemplar for each particle, in which particles learn more from highquality particles. The biogeography-based learning strategy can provide a more effective balance between exploration and exploitation for the BLPSO.

The BLPSO was applied to five test systems with various constraints such as power balance, POZs, and ramp-rate limits. Transmission losses have also been included in some systems. The experimental results show that the fuel costs obtained by BLPSO are either comparable or lower than those reported by other methods. The application to a 110unit system shows that the BLPSO is also capable of handling high-dimensional ED problems.

In the future, we are planning to extend the BLPSO to solve other more complicated ED problems, such as dynamical ED problems and environmental ED problems. We are also interested in applying the BLPSO to other optimization problems in energy field such as solar photovoltaic modeling [73].

\section{Data Availability}

The data used to support the findings of this study are available from the corresponding author upon request. 


\section{Conflicts of Interest}

The authors declare that they have no conflicts of interest.

\section{Acknowledgments}

This work was supported in part by the Natural Science Foundation of Jiangsu Province (Grant no. BK 20160540), China Postdoctoral Science Foundation (Grant no. 2016M591783), and Fundamental Research Funds for the Central Universities (Grant no. 222201717006).

\section{Supplementary Materials}

Table S1 Table S5 provides the system data of the five test systems studied in this paper. (1) Table S1: the system data of test system 1 (6-unit system). (2) Table S2: the system data of test system 2 (15-unit system). (3) Table S3: the system data of test system 3 (20-unit system). (4) Table S4: the system data of test system 4 (38-unit system). (5) Table S5: the system data of test system 5 (110-unit system). (Supplementary Materials)

\section{References}

[1] N. Ghorbani and E. Babaei, "Exchange market algorithm for economic load dispatch," International Journal of Electrical Power \& Energy Systems, vol. 75, pp. 19-27, 2016.

[2] K. T. Chaturvedi, M. Pandit, and L. Srivastava, "Self-organizing hierarchical particle swarm optimization for nonconvex economic dispatch," IEEE Transactions on Power Systems, vol. 23, no. 3, pp. 1079-1087, 2008.

[3] R. A. Jabr, A. H. Coonick, and B. J. Cory, "A homogeneous linear programming algorithm for the security constrained economic dispatch problem," IEEE Transactions on Power Systems, vol. 15, no. 3, pp. 930-936, 2000.

[4] J. P. Zhan, Q. H. Wu, C. X. Guo, and X. X. Zhou, "Fast $\lambda$-iteration method for economic dispatch with prohibited operating zones," IEEE Transactions on Power Systems, vol. 29, no. 2, pp. 990-991, 2014.

[5] Z. Li, W. Wu, B. Zhang, H. Sun, and Q. Guo, "Dynamic economic dispatch using Lagrangian relaxation with multiplier updates based on a quasi-Newton method," IEEE Transactions on Power Systems, vol. 28, no. 4, pp. 4516-4527, 2013.

[6] T. Niknam, "A new fuzzy adaptive hybrid particle swarm optimization algorithm for non-linear, non-smooth and nonconvex economic dispatch problem," Applied Energy, vol. 87, no. 1, pp. 327-339, 2010.

[7] C.-L. Chiang, "Genetic-based algorithm for power economic load dispatch," IET Generation, Transmission \& Distribution, vol. 1, no. 2, pp. 261-269, 2007.

[8] Z.-L. Gaing, "Particle swarm optimization to solving the economic dispatch considering the generator constraints," IEEE Transactions on Power Systems, vol. 18, no. 3, pp. 1187-1195, 2003.

[9] N. Noman and H. Iba, "Differential evolution for economic load dispatch problems," Electric Power Systems Research, vol. 78, no. 8, pp. 1322-1331, 2008.

[10] S. Pothiya, I. Ngamroo, and W. Kongprawechnon, "Ant colony optimisation for economic dispatch problem with non- smooth cost functions," International Journal of Electrical Power \& Energy Systems, vol. 32, no. 5, pp. 478-487, 2010.

[11] A. Vasebi, M. Fesanghary, and S. M. T. Bathaee, "Combined heat and power economic dispatch by harmony search algorithm," International Journal of Electrical Power \& Energy Systems, vol. 29, no. 10, pp. 713-719, 2007.

[12] S. Hemamalini and S. P. Simon, "Artificial bee colony algorithm for economic load dispatch problem with non-smooth cost functions," Electric Power Components and Systems, vol. 38, no. 7, pp. 786-803, 2010.

[13] M. Basu, "Teaching-learning-based optimization algorithm for multi-area economic dispatch," Energy, vol. 68, pp. 2128, 2014.

[14] S. D. Beigvand, H. Abdi, and M. La Scala, "Combined heat and power economic dispatch problem using gravitational search algorithm," Electric Power Systems Research, vol. 133, pp. 160-172, 2016.

[15] X.-S. Yang, S. S. Sadat Hosseini, and A. H. Gandomi, "Firefly algorithm for solving non-convex economic dispatch problems with valve loading effect," Applied Soft Computing, vol. 12, no. 3, pp. 1180-1186, 2012.

[16] A. Bhattacharya and P. K. Chattopadhyay, "Biogeographybased optimization for different economic load dispatch problems," IEEE Transactions on Power Systems, vol. 25, no. 2, pp. 1064-1077, 2010.

[17] U. Krishnasamy and D. Nanjundappan, "Hybrid weighted probabilistic neural network and biogeography based optimization for dynamic economic dispatch of integrated multiplefuel and wind power plants," International Journal of Electrical Power \& Energy Systems, vol. 77, pp. 385-394, 2016.

[18] R. Vijay, "Intelligent bacterial foraging optimization technique to economic load dispatch problem," International Journal of Soft Computing and Engineering (IJSCE), vol. 2, no. 2, pp. 2231-2307, 2012.

[19] E. Bijami, M. Jadidoleslam, A. Ebrahimi, J. Askari, and M. M. Farsangi, "Implementation of imperialist competitive algorithm to solve non-convex economic dispatch problem," Journal of the Chinese Institute of Engineers, vol. 37, no. 2, pp. 232-242, 2014.

[20] B. Shaw, V. Mukherjee, and S. P. Ghoshal, "Seeker optimisation algorithm: application to the solution of economic load dispatch problems," IET Generation, Transmission \& Distribution, vol. 5, no. 1, pp. 81-91, 2011.

[21] M. Pradhan, P. K. Roy, and T. Pal, "Grey wolf optimization applied to economic load dispatch problems," International Journal of Electrical Power \& Energy Systems, vol. 83, pp. 325-334, 2016.

[22] M. Modiri-Delshad and N. A. Rahim, "Solving non-convex economic dispatch problem via backtracking search algorithm," Energy, vol. 77, pp. 372-381, 2014.

[23] Y. Labbi, D. B. Attous, H. A. Gabbar, B. Mahdad, and A. Zidan, "A new rooted tree optimization algorithm for economic dispatch with valve-point effect," International Journal of Electrical Power \& Energy Systems, vol. 79, pp. 298-311, 2016.

[24] P. Subbaraj, R. Rengaraj, and S. Salivahanan, "Enhancement of self-adaptive real-coded genetic algorithm using Taguchi method for economic dispatch problem," Applied Soft Computing, vol. 11, no. 1, pp. 83-92, 2011.

[25] J. Sun, V. Palade, X.-J. Wu, W. Fang, and Z. Wang, "Solving the power economic dispatch problem with generator 
constraints by random drift particle swarm optimization," IEEE Transactions on Industrial Informatics, vol. 10, no. 1, pp. 222-232, 2013.

[26] W. T. Elsayed, Y. G. Hegazy, M. S. El-bages, and F. M. Bendary, "Improved random drift particle swarm optimization with self-adaptive mechanism for solving the power economic dispatch problem," IEEE Transactions on Industrial Informatics, vol. 13, no. 3, pp. 1017-1026, 2017.

[27] T. Niknam, H. D. Mojarrad, and M. Nayeripour, "A new fuzzy adaptive particle swarm optimization for non-smooth economic dispatch," Energy, vol. 35, no. 4, pp. 1764-1778, 2010.

[28] D. Zou, S. Li, G. G. Wang, Z. Li, and H. Ouyang, "An improved differential evolution algorithm for the economic load dispatch problems with or without valve-point effects," Applied Energy, vol. 181, pp. 375-390, 2016.

[29] A. Srinivasa Reddy and K. Vaisakh, "Shuffled differential evolution for economic dispatch with valve point loading effects," International Journal of Electrical Power \& Energy Systems, vol. 46, pp. 342-352, 2013.

[30] L. D. S. Coelho and V. C. Mariani, "An improved harmony search algorithm for power economic load dispatch," Energy Conversion and Management, vol. 50, no. 10, pp. 2522-2526, 2009.

[31] D. C. Secui, "A new modified artificial bee colony algorithm for the economic dispatch problem," Energy Conversion and Management, vol. 89, pp. 43-62, 2015.

[32] S. Ozyon and D. Aydin, "Incremental artificial bee colony with local search to economic dispatch problem with ramp rate limits and prohibited operating zones," Energy Conversion and Management, vol. 65, pp. 397-407, 2013.

[33] S. K. Gachhayat and S. K. Dash, "Non-convex multi objective economic dispatch using ramp rate biogeography based optimization," International Journal of Electrical Computer Energetic Electronic and Communication Engineering, vol. 11, pp. 545-549, 2017.

[34] H. Ma, Z. Yang, P. You, and M. Fei, "Multi-objective biogeography-based optimization for dynamic economic emission load dispatch considering plug-in electric vehicles charging," Energy, vol. 135, pp. 101-111, 2017.

[35] G. Xiong, D. Shi, and X. Duan, "Multi-strategy ensemble biogeography-based optimization for economic dispatch problems," Applied Energy, vol. 111, pp. 801-811, 2013.

[36] K. Zare, M. T. Haque, and E. Davoodi, "Solving non-convex economic dispatch problem with valve point effects using modified group search optimizer method," Electric Power Systems Research, vol. 84, no. 1, pp. 83-89, 2012.

[37] D. He, F. Wang, and Z. Mao, "A hybrid genetic algorithm approach based on differential evolution for economic dispatch with valve-point effect," International Journal of Electrical Power \& Energy Systems, vol. 30, no. 1, pp. 31-38, 2008.

[38] J. Cai, Q. Li, L. Li, H. Peng, and Y. Yang, "A hybrid FCASO-SQP method for solving the economic dispatch problems with valve-point effects," Energy, vol. 38, no. 1, pp. 346-353, 2012.

[39] S. Jiang, Z. Ji, and Y. Shen, "A novel hybrid particle swarm optimization and gravitational search algorithm for solving economic emission load dispatch problems with various practical constraints," International Journal of Electrical Power \& Energy Systems, vol. 55, pp. 628-644, 2014.
[40] S. Sayah and A. Hamouda, "A hybrid differential evolution algorithm based on particle swarm optimization for nonconvex economic dispatch problems," Applied Soft Computing, vol. 13, no. 4, pp. 1608-1619, 2013.

[41] A. Bhattacharya and P. K. Chattopadhyay, "Hybrid differential evolution with biogeography-based optimization for solution of economic load dispatch," IEEE Transactions on Power Systems, vol. 25, no. 4, pp. 1955-1964, 2010.

[42] P. K. Roy, S. Bhui, and C. Paul, "Solution of economic load dispatch using hybrid chemical reaction optimization approach," Applied Soft Computing, vol. 24, pp. 109-125, 2014.

[43] M. J. Morshed and A. Asgharpour, "Hybrid imperialist competitive-sequential quadratic programming (HIC-SQP) algorithm for solving economic load dispatch with incorporating stochastic wind power: a comparative study on heuristic optimization techniques," Energy Conversion and Management, vol. 84, pp. 30-40, 2014.

[44] A. Meng, J. Li, and H. Yin, "An efficient crisscross optimization solution to large-scale non-convex economic load dispatch with multiple fuel types and valve-point effects," Energy, vol. 113, pp. 1147-1161, 2016.

[45] R. Eberhart and J. Kennedy, "A new optimizer using particle swarm theory," in Micro Machine and Human Science, 1995. MHS '95., Proceedings of the Sixth International Symposium on, pp. 39-43, Nagoya, Japan, Japan, October 1995.

[46] J. J. Liang, A. K. Qin, P. N. Suganthan, and S. Baskar, "Comprehensive learning particle swarm optimizer for global optimization of multimodal functions," IEEE Transactions on Evolutionary Computation, vol. 10, no. 3, pp. 281-295, 2006.

[47] R. Cheng and Y. Jin, "A social learning particle swarm optimization algorithm for scalable optimization," Information Sciences, vol. 291, pp. 43-60, 2015.

[48] X. Chen, H. Tianfield, C. Mei, W. Du, and G. Liu, "Biogeography-based learning particle swarm optimization," Soft Computing, vol. 21, no. 24, pp. 7519-7541, 2017.

[49] S. Dan, "Biogeography-based optimization," IEEE Transactions on Evolutionary Computation, vol. 12, pp. 702-713, 2008.

[50] X. Chen, H. Tianfield, W. Du, and G. Liu, "Biogeographybased optimization with covariance matrix based migration," Applied Soft Computing, vol. 45, pp. 71-85, 2016.

[51] W. Guo, W. Li, Q. Zhang, L. Wang, Q. Wu, and H. Ren, "Biogeography-based particle swarm optimization with fuzzy elitism and its applications to constrained engineering problems," Engineering Optimization, vol. 46, no. 11, pp. 1465-1484, 2014.

[52] H. Mo and L. Xu, "Research of biogeography particle swarm optimization for robot path planning," Neurocomputing, vol. 148, pp. 91-99, 2015.

[53] Z.-L. Gaing, "Closure to "Discussion of 'Particle swarm optimization to solving the economic dispatch considering the generator constraints"', "IEEE Transactions on Power Systems, vol. 19, no. 4, pp. 2122-2123, 2004.

[54] A. I. Selvakumar and K. Thanushkodi, "A new particle swarm optimization solution to nonconvex economic dispatch problems," IEEE Transactions on Power Systems, vol. 22, no. 1, pp. 42-51, 2007.

[55] S. Pothiya, I. Ngamroo, and W. Kongprawechnon, "Application of multiple tabu search algorithm to solve dynamic economic dispatch considering generator constraints," Energy Conversion and Management, vol. 49, no. 4, pp. 506-516, 2008. 
[56] I. Ciornei and E. Kyriakides, "A GA-API solution for the economic dispatch of generation in power system operation," IEEE Transactions on Power Systems, vol. 27, no. 1, pp. 233242, 2012.

[57] W. T. Elsayed and E. F. El-Saadany, "A fully decentralized approach for solving the economic dispatch problem," IEEE Transactions on Power Systems, vol. 30, no. 4, pp. 2179-2189, 2015.

[58] B. R. Adarsh, T. Raghunathan, T. Jayabarathi, and X.-S. Yang, "Economic dispatch using chaotic bat algorithm," Energy, vol. 96, pp. 666-675, 2016.

[59] T. Niknam, H. D. Mojarrad, H. Z. Meymand, and B. B. Firouzi, "A new honey bee mating optimization algorithm for nonsmooth economic dispatch," Energy, vol. 36, no. 2, pp. 896908, 2011.

[60] J.-B. Park, Y.-W. Jeong, J.-R. Shin, and K. Y. Lee, "An improved particle swarm optimization for nonconvex economic dispatch problems," IEEE Transactions on Power Systems, vol. 25, no. 1, pp. 156-166, 2010.

[61] S. Chalermchaiarbha and W. Ongsakul, "Stochastic weight trade-off particle swarm optimization for nonconvex economic dispatch," Energy Conversion and Management, vol. 70, pp. 66-75, 2013.

[62] V. S. Aragón, S. C. Esquivel, and C. A. Coello Coello, "An immune algorithm with power redistribution for solving economic dispatch problems," Information Sciences, vol. 295, pp. 609-632, 2015.

[63] Q. Qin, S. Cheng, X. Chu, X. Lei, and Y. Shi, "Solving nonconvex/non-smooth economic load dispatch problems via an enhanced particle swarm optimization," Applied Soft Computing, vol. 59, pp. 229-242, 2017.

[64] C.-T. Su and C.-T. Lin, "New approach with a Hopfield modeling framework to economic dispatch," IEEE Transactions on Power Systems, vol. 15, no. 2, pp. 541-545, 2000.

[65] A. Y. Abdelaziz, S. F. Mekhamer, M. A. L. Badr, and M. Z. Kamh, "Economic dispatch using an enhanced Hopfield neural network," Electric Power Components and Systems, vol. 36, no. 7, pp. 719-732, 2008.

[66] M. Moradi-Dalvand, B. Mohammadi-Ivatloo, A. Najafi, and A. Rabiee, "Continuous quick group search optimizer for solving non-convex economic dispatch problems," Electric Power Systems Research, vol. 93, pp. 93-105, 2012.

[67] K. T. Chaturvedi, M. Pandit, and L. Srivastava, "Particle swarm optimization with time varying acceleration coefficients for non-convex economic power dispatch," International Journal of Electrical Power \& Energy Systems, vol. 31, no. 6, pp. 249257, 2009.

[68] M. Fesanghary and M. M. Ardehali, "A novel meta-heuristic optimization methodology for solving various types of economic dispatch problem," Energy, vol. 34, no. 6, pp. 757-766, 2009.

[69] A. K. Barisal and R. C. Prusty, "Large scale economic dispatch of power systems using oppositional invasive weed optimization," Applied Soft Computing, vol. 29, pp. 122-137, 2015.

[70] S. Orero and M. R. Irving, "Large scale unit commitment using a hybrid genetic algorithm," International Journal of Electrical Power \& Energy Systems, vol. 19, no. 1, pp. 45-55, 1997.

[71] K. K. Vishwakarma and H. M. Dubey, "Simulated annealing based optimization for solving large scale economic load dispatch problems," International journal of engineering research \& technology (IJERT), vol. 1, 2012.
[72] K. Bhattacharjee, A. Bhattacharya, and S. H. n. Dey, "Oppositional real coded chemical reaction optimization for different economic dispatch problems," International Journal of Electrical Power \& Energy Systems, vol. 55, pp. 378-391, 2014.

[73] X. Chen, B. Xu, C. Mei, Y. Ding, and K. Li, “Teaching-learning-based artificial bee colony for solar photovoltaic parameter estimation," Applied Energy, vol. 212, pp. 1578-1588, 2018. 


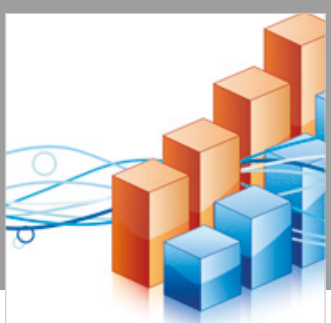

Advances in

Operations Research

\section{-n-m}
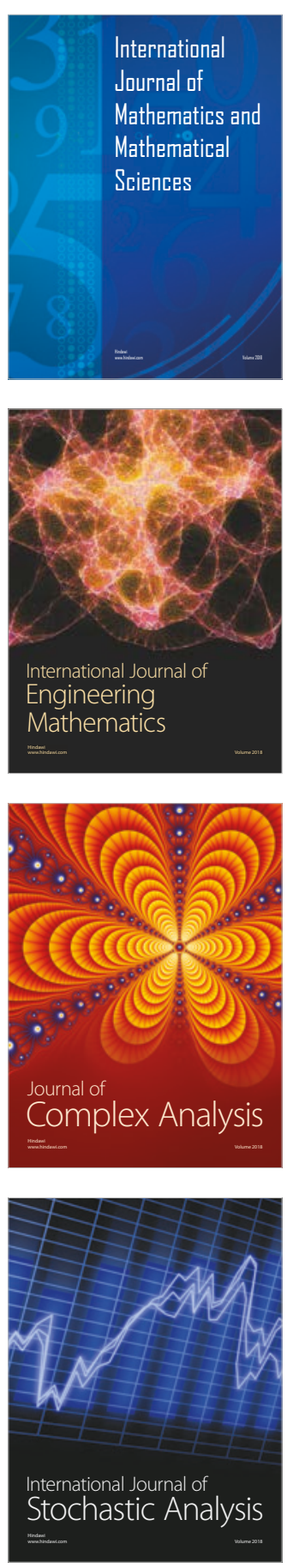
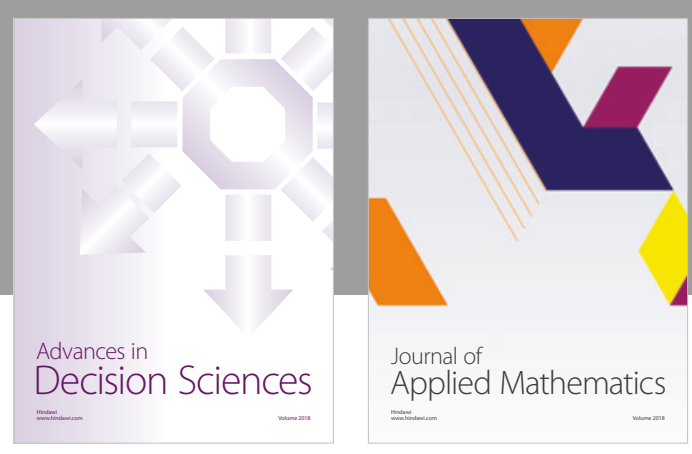

Journal of

Applied Mathematics
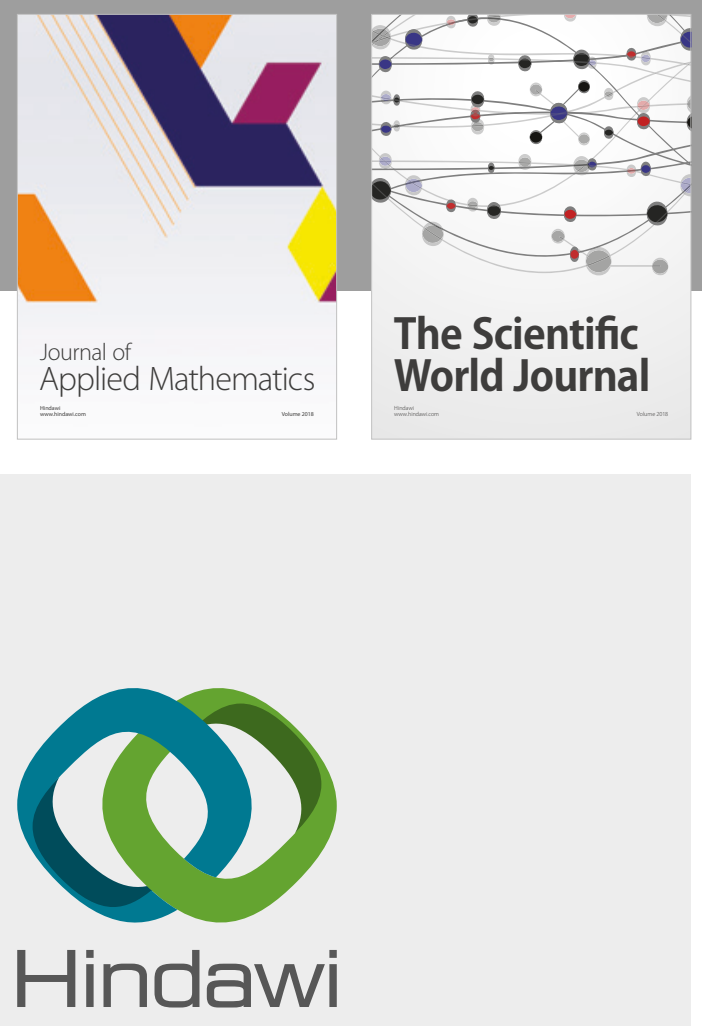

Submit your manuscripts at

www.hindawi.com

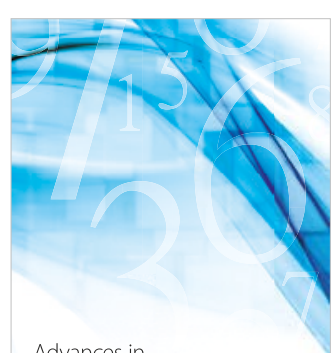

Advances in
Numerical Analysis
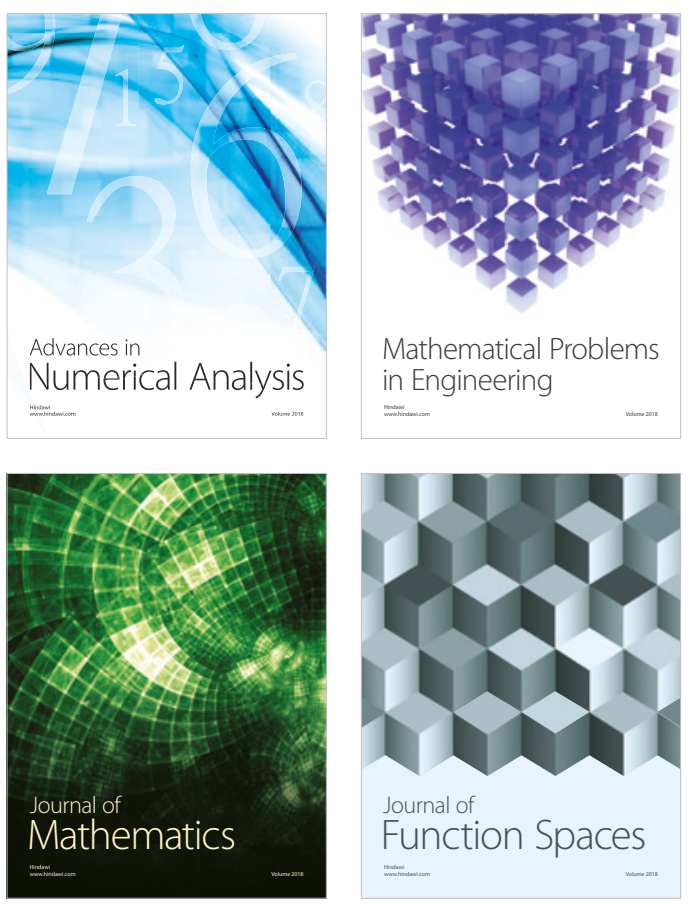

Mathematical Problems in Engineering

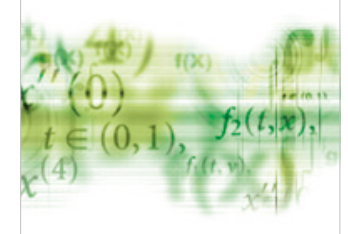

International Journal of

Differential Equations

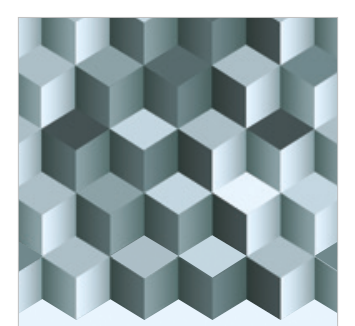

Journal of

Function Spaces
The Scientific

World Journal

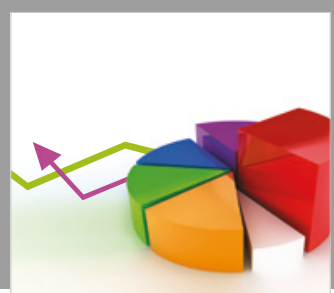

Journal of

Probability and Statistics
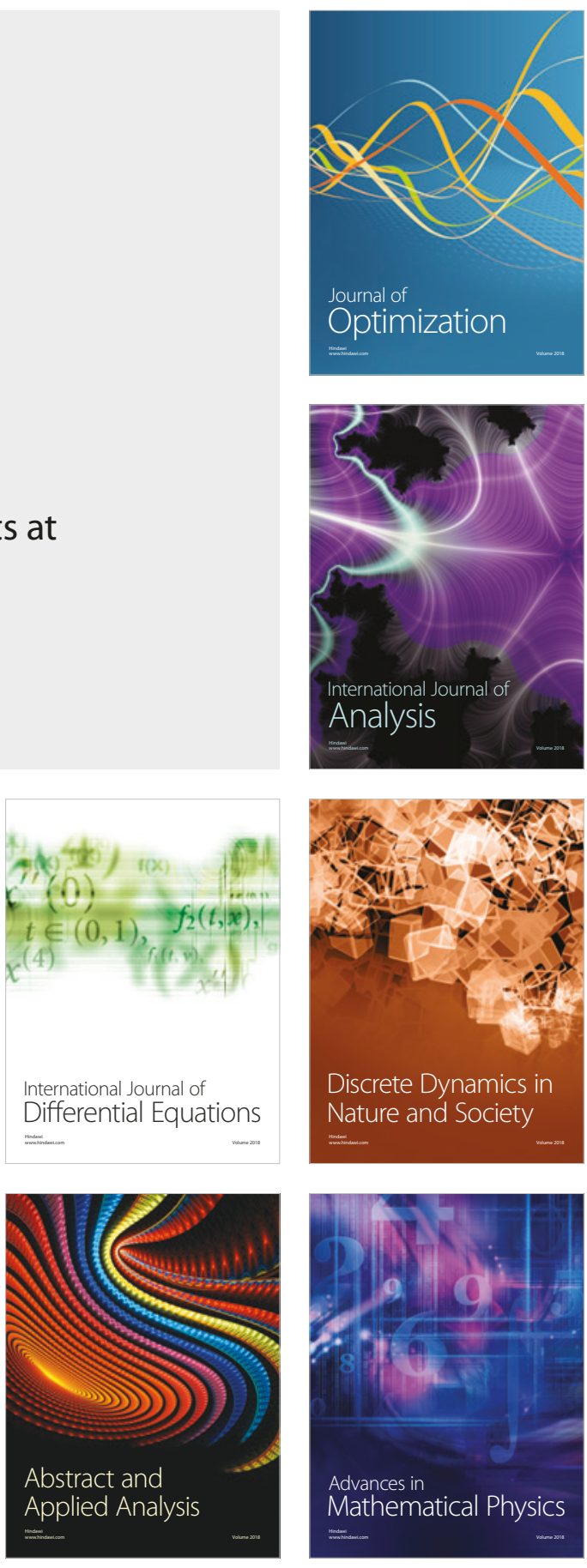